BRAZIULIAN JOURNAL

OF MEDICAL AND BIOLOGICAL RESFARCH

www.bjournal.com.br
ISSN 0100-879X

Volume 44 (12) 1194-1298 December 2011

BIOMEDICAL SCIENCES

AND

CLINICAL INVESTIGATION

Braz J Med Biol Res, December 2011, Volume 44(12) 1291-1298

doi: 10.1590/S0100-879X2011007500146

Implications of extubation failure and prolonged mechanical ventilation in the postoperative period following elective intracranial surgery

M.C. Vidotto, L.C. Sogame, M.R. Gazzotti, M. Prandini and J.R. Jardim

The Brazilian Journal of Medical and Biological Research is partially financed by

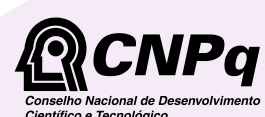

da Ciência e Tecnologia

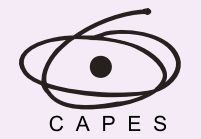

Ministério da Educação

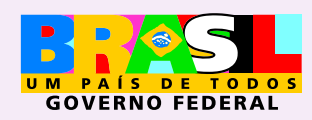

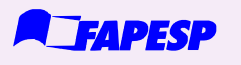

Institutional Sponsors
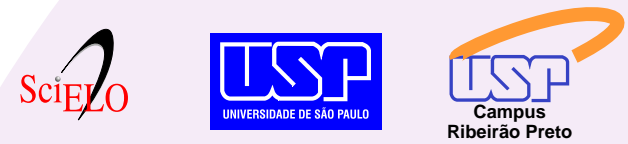

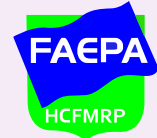

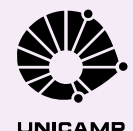

UNICAMP
ФSHIMADZU

Explore High - Performance MS Orbitrap Technology In Proteomics \& Metabolomics

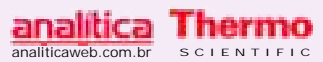




\title{
Implications of extubation failure and prolonged mechanical ventilation in the postoperative period following elective intracranial surgery
}

\author{
M.C. Vidotto ${ }^{1}$, L.C. Sogame ${ }^{2}$, M.R. Gazzotti ${ }^{3}$, M. Prandini ${ }^{4}$ and J.R. Jardim ${ }^{3}$ \\ ${ }^{1}$ Departamento de Fisioterapia, Universidade Federal de São Paulo, Santos, SP, Brasil \\ ${ }^{2}$ Departamento de Fisioterapia, Escola Superior de Ciências, Santa Casa de Misericórdia de Vitória, \\ Vitória, ES, Brasil \\ ${ }^{3}$ Departamento de Medicina, Universidade Federal de São Paulo, São Paulo, SP, Brasil \\ ${ }^{4}$ Departamento de Neurocirurgia, Universidade Federal de São Paulo, São Paulo, SP, Brasil
}

\begin{abstract}
Patients undergoing neurosurgery are predisposed to a variety of complications related to mechanical ventilation (MV). There is an increased incidence of extubation failure, pneumonia, and prolonged MV among such patients. The aim of the present study was to assess the influence of extubation failure and prolonged MV on the following variables: postoperative pulmonary complications (PPC), mortality, reoperation, tracheostomy, and duration of postoperative hospitalization following elective intracranial surgery. The study involved a prospective observational cohort of 317 patients submitted to elective intracranial surgery for tumors, aneurysms and arteriovenous malformation. Preoperative assessment was performed and patients were followed up for the determination of extubation failure and prolonged MV ( $>48 \mathrm{~h})$ until discharge from the hospital or death. The occurrence of PPC, incidence of death, the need for reoperation and tracheostomy, and the length of hospitalization were assessed during the postoperative period. Twenty-six patients (8.2\%) experienced extubation failure and $30(9.5 \%)$ needed prolonged MV after surgery. Multivariate analysis showed that extubation failure was significant for the occurrence of death (OR $=8.05$ [1.88; 34.36]), PPC (OR = 11.18 [2.27; 55.02]) and tracheostomy $(\mathrm{OR}=7.8$ [1.12; 55.07]). Prolonged MV was significant only for the occurrence of PPC $(\mathrm{OR}=4.87$ [1.3; 18.18]). Elective intracranial surgery patients who experienced extubation failure or required prolonged MV had a higher incidence of PPC, reoperation and tracheostomy and required a longer period of time in the ICU. Level of consciousness and extubation failure were associated with death and PPC. Patients who required prolonged MV had a higher incidence of extubation failure.
\end{abstract}

Key words: Neurosurgery; Craniotomy; Ventilator weaning; Intratracheal intubation; Postoperative period

\section{Introduction}

Extubation failure is defined as the reinstitution of respiratory support from 24 to $72 \mathrm{~h}$ following the scheduled extubation. This condition occurs in 2 to $25 \%$ of extubated patients (1-3). Extubation failure increases the incidence of mortality, pneumonia, number of days in the intensive care unit (ICU) and hospital, time spent on mechanical ventilation (MV), hospital costs, and the need for a tracheostomy (4-5).

The time interval for defining prolonged MV or extubation failure has yet to be established, ranging from 6 to $48 \mathrm{~h}$ in recent studies (6-9) and from 2 to 7 days in older studies
$(10,11)$. The maintenance of patients on MV for a prolonged length of time can cause complications such as development of oxygen toxicity, larynx injuries, tracheal stenosis, selective intubation, sinusitis, barotrauma, reduced cardiac output, pneumonia, and psychological problems (12). There is evidence that maintenance of a patient on MV for more than $72 \mathrm{~h}$ leads to depletion of oxidative enzymes in the respiratory muscles and neuromyopathy (13).

Patients undergoing neurosurgery are predisposed to a variety of complications related to MV. A number of studies have demonstrated an increased incidence of reintuba-

Correspondence: J.R. Jardim, Disciplina de Pneumologia, UNIFESP, Rua Botucatu, 740, 3a andar, 04023-062 São Paulo, SP, Brasil. Fax: +55-115573-5035. E-mail: milenavidotto@hotmail.com

Received October 18, 2010. Accepted September 22, 2011. Available online October 28, 2011. Published November $28,2011$. 
tion, pneumonia, and prolonged MV among such patients $(2-5,7,9,14,15)$.

The aim of the present study was to assess the influence of extubation failure and prolonged MV on the following variables: postoperative pulmonary complications, mortality, reoperation, tracheostomy, and length of hospitalization in the postoperative period following elective intracranial surgery.

\section{Material and Methods}

\section{Study population}

A prospective observational cohort study was conducted from July 2005 to July 2009 at Hospital São Paulo, Universidade Federal de São Paulo (UNIFESP), Brazil. Potential subjects were scheduled for elective intracranial surgery for treatment of a tumor, aneurysm, arteriovenous malformation, intracranial hematoma, or abscess. Patients subjected to surgery under general anesthesia and patients maintaining spontaneous breathing before surgery were included in the study. Patients who died or received a tracheostomy before weaning from MV were excluded from the study. A total of 434 patients were assessed in the preoperative period, 317 of whom were included in the study. Among the 117 patients who were not included, 21 died before weaning from MV, 11 underwent tracheostomy before weaning, 33 did not undergo the initially proposed surgery, 15 had the surgery cancelled, 5 required orotracheal intubation before surgery, 28 were referred to a different ICU during the postoperative period, and 4 had incomplete data regarding the surgery. The study was approved by the Research and Ethics Committee of Universidade Federal de São Paulo and all patients gave informed written consent to participate.

\section{Data collection}

Data were collected daily by the same members of the research group using an evaluation form. After the surgical procedure, patients who remained intubated after surgery were referred to the neurosurgical ICU and maintained under MV using a Bear 1000 ventilator (Allied Health Care Productions, USA), a Monterey ventilator (Takaoka, Brazil), or a Bird 8400 STI PC Vaps ventilator (Bird, USA). The ventilators were maintained on a volume-cycled synchronized intermittent mandatory ventilation (SIMV) mode, with the following settings: tidal volume of 6-8 mL/kg; $\mathrm{FIO}_{2}$ to maintain arterial oxyhemoglobin saturation over $93 \%$, positive end-expiratory pressure (PEEP) of $5 \mathrm{cmH}_{2} \mathrm{O}$, and a respiratory frequency between 12 and 16 breaths/min to maintain $\mathrm{PaCO}_{2}$ between 35 and $45 \mathrm{mmHg}$.

\section{Weaning process}

Patients were subjected to a daily screening of weaning parameters, and the weaning process was initiated when they fulfilled the following criteria: a) resolved need for sedatives and vasoactive drugs; b) hemodynamic stability; c) adequate respiratory drive, with absence of apnea or tachypnea (respiratory rate less than $35 \mathrm{rpm}$ ); d) no immediate upcoming surgery scheduled; e) laboratory exam results within normal ranges; f) arterial blood gases within normal ranges ( $\mathrm{pH}$ between 7.35 and 7.45; $\mathrm{PaCO}_{2}$ between 30 to $40 \mathrm{mmHg}$ ); g) $\mathrm{PaO}_{2}>60 \mathrm{mmHg}$, with $\mathrm{FiO}_{2}$ $\leq 0.4$ and PEEP $\leq 5 \mathrm{cmH}_{2} \mathrm{O} ; \mathrm{h}$ ) resolution of conditions requiring maintenance of the patient on MV after surgery; i) Glasgow Coma Scale equal to or greater than 8, and j) agreement by the neurosurgeon in charge.

Patients who fulfilled the weaning criteria were subjected to a spontaneous breathing trial (SBT). The SBT was performed once a day and consisted of 30- to 120-min trials of spontaneous breathing performed on a T-tube or pressure support of $\leq 8 \mathrm{cmH}_{2} \mathrm{O}$ and a PEEP level of $\leq 5 \mathrm{cmH}_{2} \mathrm{O}$. All patients ultimately passed an SBT and were extubated. The criteria used to define failure to tolerate the SBT were: a) oxygen saturation $<90 \%$; b) respiratory rate of $>35$ breaths/min for $>10 \mathrm{~min}$; c) a $>20 \%$ decrease or increase in systolic blood pressure; d) signs of increased breathing efforts for $>15 \mathrm{~min}$, and e) diaphoresis or agitation. An SBT was considered to have failed if any 2 of the above-listed criteria were met, in which case, SBT was stopped and MV was reinstituted at the original settings.

\section{Extubation failure}

After successful completion of an SBT, patients were extubated. On the basis of the Brazilian Consensus of Mechanical Ventilation (16), extubation failure was considered when patients needed reintubation within $48 \mathrm{~h}$. The decision to reintubate the patient was based on confirmation of clinical deterioration as evidenced by at least one of the following criteria: a decrease in mental status, a worsening of arterial $\mathrm{pH}$ or $\mathrm{PCO}_{2}$, a decrease in the oxygen saturation to $<90 \%$ despite an inspired fraction of oxygen $>0.5$, and increased signs of respiratory effort (e.g., tachypnea, the use of accessory respiratory muscles, and/or thoracoabdominal paradox).

\section{Prolonged MV}

Prolonged MV was considered when patients needed ventilatory support for more than $48 \mathrm{~h}$ after the completion of surgery. A cutoff of $48 \mathrm{~h}$ was used because the majority of previous studies also selected this value.

\section{Consciousness level}

The assessment of consciousness level in the postoperative period was based on a modified Glasgow Coma Scale (GCS). The modification was due to the fact that patients were under MV and orotracheal intubation, the verbal response that would normally be scored as 5 was scored only as 1 . This was associated with the letter $\mathrm{T}$, indicating the need for an artificial airway and the inability to provide a verbal response. We calculated the best motor 
response and eye opening, and scored a verbal response as $1 \mathrm{~T}$. The level of consciousness was characterized as normal for patients with GCS scores of $11 \mathrm{~T}$ and altered with scores of $8 \mathrm{~T}$ to $10 \mathrm{~T}$ (9).

\section{Postoperative pulmonary complications}

The diagnoses of postoperative pulmonary complications were defined by the medical team as well as the physiotherapy and nursing teams. The following definitions for postoperative pulmonary complications were used (16): a) acute respiratory infection: occurrence of either pneumonia or purulent tracheobronchitis. Pneumonia diagnosis was established by the presence of lung infiltration in the thorax radiograph associated with at least 2 of the following signs: purulent tracheobronchial secretion, an increase in body temperature above $38.3^{\circ} \mathrm{C}$ and a $25 \%$ increase in the basal number of circulating leukocytes. Purulent tracheobronchitis was diagnosed when there was an increase in the amount, or change in color or purulence of the tracheobronchial secretion associated with a normal thorax radiograph. b) Atelectasis was considered to be a pulmonary complication when the appearance of acute respiratory symptoms was associated with radiological imaging. c) Bronchospasm: wheezing detectable with a stethoscope associated with the development of acute respiratory symptoms and the need for medication therapy.

The incidence of death, the need for reoperation and tracheostomy, and the length of hospitalization were monitored during the postoperative period.

\section{Statistical methods}

Categorical variables are summarized as absolute and relative (percentage) frequencies. Numerical variables are reported as means \pm SD. Only the length of admission to the ICU is reported as median and interquartile range (Q1-Q3). To evaluate the objectives of the present study, five primary outcomes were considered: postoperative pulmonary complications, death, reoperation, tracheostomy, and the length of ICU stay.

In univariate analysis, the chi-square test or the Fisher exact test was used to determine associations between categorical variables and outcome. The length of stay in the ICU was determined using the Mann-Whitney test for nonparametric data since the distribution of this variable was not normal.

A logistic regression model was used to assess the simultaneous influence of clinical and surgical variables on the outcomes. Variables with descriptive levels ( $P$ values) lower than 0.10 in the univariate analysis were included in the multivariate model. All interaction effects between variables were analyzed.

Estimates of event probabilities were calculated from the adjustment of the logistic regression models, (postoperative pulmonary complications, death, reoperation, tracheostomy, and the length of ICU stay) according to the explicative variables (extubation failure and prolonged MV) included in the models. The SPSS (version 13.0) statistical software program was employed.

\section{Results}

Among the 317 patients included in the study, 26 (8.2\%) experienced extubation failure, $30(9.5 \%)$ needed prolonged MV after surgery, and $8(2.5 \%)$ had extubation failure as well as a requirement for prolonged MV. Of the 26 patients who experienced extubation failure, 17 had altered levels of consciousness, 3 had seizures, 5 had respiratory distress (3 respiratory distress cases were related to upper airway obstruction and 2 were related to pneumonia), and 1 patient required reoperation due to a hematoma. Among the 8 patients who experienced extubation failure and prolonged MV, 5 failed extubation for respiratory distress, 2 had altered levels of consciousness, and 1 patient had a seizure. Table 1 lists the characteristics of the 317 patients included in the study. The clinical and surgical variables regarding the occurrence of extubation failure and prolonged MV are shown in Table 2.

Sixty-five patients $(20 \%)$ developed postoperative pulmonary complications, $18(6 \%)$ died, $17(5 \%)$ required further surgical intervention following extubation, and 11 (3\%) required a tracheostomy. The median stay in the ICU was 2 days (interquartile range: 1-6). The median ICU stay among patients who experienced extubation failure was 15 days (interquartile range: 10-30). This period is longer than the median ICU stay of 2 days for patients who experienced successful extubation (interquartile range: 1-5). Of the 18 patients who died, $61 \%$ evolved toward brain death, $28 \%$ experienced respiratory insufficiency, and 2 patients died as a result of cardiac arrest.

Patients who experienced extubation failure had a higher incidence of postoperative pulmonary complications (85\%), a higher incidence of death (38\%), a greater need for an additional surgical procedure (38\%), a higher incidence of tracheostomy, and a longer stay in the ICU during the postoperative period (Table 3).

The median ICU stay among patients who required prolonged MV was 13.5 days (interquartile range 8.7-30). This is in contrast to the 2-day median ICU stay of patients who did not need MV (interquartile range: 1-5). Patients who developed prolonged MV had a higher incidence of postoperative pulmonary complications $(80 \%)$, a greater need for additional surgery (70\%), a greater need for tracheostomy (20\%), a longer stay in the ICU during the postoperative period, and a higher incidence of extubation failure $(26 \%)$ (Table 3$)$.

Univariate analysis was used to determine associations between clinical and surgical variables and the outcomes. The clinical and surgical variables analyzed in the univariate analysis during the preoperative period were: gender, age, respiratory symptoms, smoking status, pulmonary 
disease, associated diseases, previous craniotomy, level of consciousness, and neurological diagnosis. The clinical and surgical variables analyzed in the univariate analysis during the intraoperative period were the location and duration of surgery. The clinical and surgical variables analyzed in the univariate analysis during the postoperative period were level of consciousness at extubation, MV $>48 \mathrm{~h}$, extubation failure, reoperation, and ICU stay. The outcomes considered were death, postoperative pulmonary complications, and tracheostomy.

The following variables were considered for multivariate analysis: age, extubation failure, MV $>48 \mathrm{~h}$, level of consciousness during the preoperative and postoperative periods, reoperation, duration of surgery, and the length of ICU stay. Interactions between variables were investigated, but none proved to be significant. Extubation failure and the level of consciousness during the postoperative period were identified as significant variables for the occurrence of death. For the occurrence of postoperative pulmonary complications, the important variables were extubation failure, $\mathrm{MV}>48 \mathrm{~h}$, level of consciousness during the postoperative period, and ICU stay. For the occurrence of tracheostomy, the variables considered were extubation failure and ICU stay (Table 4).

The likelihood of the occurrence of postoperative pulmonary complications, death, reoperation, tracheostomy, and a prolonged ICU stay ( $>5$ days) was estimated for patients admitted for elective intracranial surgery with considerations regarding the incidence of extubation failure and prolonged MV (Table 5).

\section{Discussion}

There was an $8.2 \%$ incidence of extubation failure and a $9.5 \%$ incidence of prolonged MV in patients admitted for elective intracranial surgery. Both extubation failure and prolonged MV influenced the development of postoperative pulmonary complications, the incidence of reoperation, the need for tracheostomy, and the length of ICU stay. Level of consciousness was found to be an important risk factor for death and postoperative pulmonary complications. Prolonged MV and death were found to be more likely for patients who experienced extubation failure.

Other studies have reported that extubation failure increases the risk of pulmonary complications, mortality, duration of MV, and an increased length of ICU stay $(5,6,17)$. The need for reintubation is a risk factor for the development of pulmonary infection $(5,18,19)$ because it favors bronchoaspiration and alterations in mucociliary clearance, which may lead to bacterial contamination and colonization of the airways $(14,20)$. Also, extubation failure is directly related to altered level of consciousness (2), probably due to the fact that patients with a lower level of consciousness exhibit large amounts of secretions, cough deficiency and swallowing deficiency.
Table 1. Distribution of 317 patients submitted to intracranial surgery according to demographic characteristics.

\begin{tabular}{|c|c|}
\hline Variables & $\begin{array}{c}\text { Means } \pm \text { SD or } \\
\text { number }(\%)\end{array}$ \\
\hline Age (years) & $46 \pm 14$ \\
\hline Males & $138(44 \%)$ \\
\hline Respiratory symptoms & $31(13.1 \%)$ \\
\hline \multicolumn{2}{|l|}{ Smoking status } \\
\hline Never & $151(48 \%)$ \\
\hline Stopped & $68(21 \%)$ \\
\hline Pack years & $22 \pm 18$ \\
\hline Current smoker & $98(31 \%)$ \\
\hline Pack years & $28 \pm 19$ \\
\hline Pulmonary disease & $28(9 \%)$ \\
\hline Asthma & 7 \\
\hline Neoplasm & 9 \\
\hline Emphysema & 7 \\
\hline Bronchitis & 5 \\
\hline Clinical disease & $90(28 \%)$ \\
\hline SAH & 86 \\
\hline Diabetes mellitus & 13 \\
\hline Cardiac arrhythmia & 6 \\
\hline Heart diseases & 4 \\
\hline Stroke & 2 \\
\hline \multicolumn{2}{|l|}{ Neurological disease } \\
\hline Tumoral lesions & $197(62 \%)$ \\
\hline Aneurysm & $102(32 \%)$ \\
\hline AVM & $18(6 \%)$ \\
\hline \multicolumn{2}{|l|}{ Site of surgery } \\
\hline Supratentorial & $264(83 \%)$ \\
\hline Infratentorial & $53(17 \%)$ \\
\hline Duration of MV (h) & $26(55)$ \\
\hline Duration of surgery (min) & $302(84)$ \\
\hline $\begin{array}{l}\text { Low level of consciousness - preoperative } \\
\text { period }\end{array}$ & $29(9 \%)$ \\
\hline
\end{tabular}

$\mathrm{SAH}=$ systemic arterial hypertension; $\mathrm{AVM}=$ arteriovenous malformation; $M V=$ mechanical ventilation.

Regardless of the occurrence of extubation failure, patients with neurological disorders are usually susceptible to pulmonary complications with pneumonia being the most frequent condition (7,19,21-23). Respiratory infection also occurs frequently after surgery and especially after neurosurgery $(9,24-27)$. Sogame et al. (15) evaluated 236 patients who underwent elective craniotomy and identified a $25 \%$ incidence of postoperative pulmonary complications, especially respiratory infections. These authors also found that postoperative pulmonary complications were a determinant for death. The higher incidence of death in our study of patients who experienced extubation failure and had altered level of consciousness does not necessarily 
Table 2. Univariate analysis of clinical and surgical variables regarding the occurrence of extubation failure and prolonged mechanical ventilation.

\begin{tabular}{|c|c|c|c|c|}
\hline Variable & Success $(N=291)$ & Failure (N = 26) & $\mathrm{MV} \leq 48 \mathrm{~h}(\mathrm{~N}=287)$ & $\mathrm{MV}>48 \mathrm{~h}(\mathrm{~N}=30)$ \\
\hline \multicolumn{5}{|l|}{ Gender } \\
\hline Female & $160(55 \%)$ & $19(73 \%)$ & $121(42 \%)$ & $17(57 \%)$ \\
\hline Male & $131(45 \%)$ & $7(27 \%)$ & $166(58 \%)$ & $13(43 \%)$ \\
\hline Age (mean years $\pm S D$ ) & $46(14.2)$ & $49(15.2)$ & $47(14)$ & $45(17)$ \\
\hline \multicolumn{5}{|l|}{ Preoperative consciousness level } \\
\hline Altered & $27(9 \%)$ & $2(7 \%)$ & $22(7 \%)$ & $7(23 \%)^{*}$ \\
\hline \multicolumn{5}{|l|}{ Previous craniotomy } \\
\hline Yes & $52(18 \%)$ & $5(19 \%)$ & $53(18 \%)$ & $4(13 \%)$ \\
\hline \multicolumn{5}{|l|}{ Respiratory symptoms } \\
\hline Present & $35(12 \%)$ & $3(11 \%)$ & $42(14 \%)$ & $3(10 \%)$ \\
\hline \multicolumn{5}{|l|}{ Previous pneumopathy } \\
\hline Present & $27(9 \%)$ & $1(4 \%)$ & $23(8 \%)$ & $5(17 \%)$ \\
\hline \multicolumn{5}{|l|}{ Smoking status } \\
\hline Smoker & $92(31 \%)$ & $6(23 \%)$ & $92(32 \%)$ & $6(20 \%)$ \\
\hline Ex-smoker & $61(20 \%)$ & $7(27 \%)$ & $64(22 \%)$ & $4(13 \%)$ \\
\hline \multicolumn{5}{|l|}{ Associated disease } \\
\hline Present & $83(28 \%)$ & $7(27 \%)$ & $82(28 \%)$ & $8(27 \%)$ \\
\hline \multicolumn{5}{|l|}{ Diagnosis } \\
\hline Tumorous lesion & $182(62 \%)$ & $15(58 \%)$ & $175(61 \%)$ & $22(73 \%)$ \\
\hline Aneurysm & $92(32 \%)$ & $10(38 \%)$ & $97(34 \%)$ & $5(17 \%)$ \\
\hline AVM & $17(6 \%)$ & $1(4 \%)$ & $15(5 \%)$ & $3(10 \%)$ \\
\hline \multicolumn{5}{|l|}{ Location of surgery } \\
\hline Supratentorial & $243(84 \%)$ & $21(81 \%)$ & $239(83 \%)$ & $25(83 \%)$ \\
\hline Infratentorial & $48(16 \%)$ & $5(19 \%)$ & $48(17 \%)$ & $5(17 \%)$ \\
\hline \multicolumn{5}{|l|}{ LC at extubation } \\
\hline Altered & $30(10 \%)$ & $11(42 \%)^{\star *}$ & - & - \\
\hline \multicolumn{5}{|l|}{ LC during postoperative period } \\
\hline Altered & - & - & $61(21 \%)$ & $26(87 \%)^{\star \star}$ \\
\hline Duration of surgery (mean minutes $\pm S D$ ) & $303(83.5)$ & $291(109.3)$ & $296(79)$ & $355(112)^{*}$ \\
\hline \multicolumn{5}{|l|}{ MV duration } \\
\hline$\leq 24 \mathrm{~h}$ & $239(82 \%)$ & $16(61 \%)$ & - & - \\
\hline $24 \dashv 48 \mathrm{~h}$ & $29(10 \%)$ & $2(8 \%)$ & & \\
\hline$>48 \mathrm{~h}$ & $23(8 \%)$ & $8(31 \%)^{*}$ & & \\
\hline
\end{tabular}

Data are reported as number with percent in parentheses unless otherwise stated. AVM = arteriovenous malformation; LC = level of consciousness; MV = mechanical ventilation. ${ }^{*} \mathrm{P}<0.05$, success or MV $\leq 48 \mathrm{~h}$ compared to failure or MV $>48 \mathrm{~h}$ (chisquare test); ${ }^{* *} \mathrm{P}<0.001$, success or $\mathrm{MV} \leq 48 \mathrm{~h}$ compared to failure or $\mathrm{MV}>48 \mathrm{~h}$ (chi-square test).

suggest an increase in mortality caused by the failure or the low level of consciousness, but identifies a group with a greater risk of fatal complications following elective intracranial surgery.

In the present study, 38\% of the patients who experienced extubation failure required further surgical intervention, whereas just $2 \%$ of those who were successfully extubated required further surgery. We found an association between extubation failure and further surgical intervention. This association could be due to a reduced level of consciousness as a result of increased intracranial pressure, indicating a secondary problem that frequently requires an additional surgical approach.

A low incidence of extubation failure was observed in the present study (8.2\%). However, patients who experienced failure spent a longer time in the ICU, which may have had a considerable impact on the cost-effectiveness of neurosurgery. Such findings emphasize the importance of early identification of risk factors for extubation failure among intracranial surgery patients so that prophylactic measures can be adopted and the practice of early extubation can be modified. 
Table 3. Variables related to extubation failure and prolonged mechanical ventilation according to the development of pulmonary complications, mortality, reoperation, and length of hospital stay in the postoperative period.

\begin{tabular}{lcccc}
\hline Variables & Success $(\mathrm{N}=291)$ & Failure $(\mathrm{N}=26)$ & $\mathrm{MV} \leq 48 \mathrm{~h}(\mathrm{~N}=287)$ & $\mathrm{MV}>48 \mathrm{~h}(\mathrm{~N}=30)$ \\
\hline PPC & $43(15 \%)$ & $22(85 \%)^{*}$ & $41(14 \%)$ & $24(80 \%)^{*}$ \\
Death & $8(3 \%)$ & $10(38 \%)^{*}$ & $14(5 \%)$ & $4(13 \%)$ \\
Reoperation & $7(2 \%)$ & $10(38 \%)^{*}$ & $11(4 \%)$ & $9(30 \%)^{*}$ \\
Tracheostomy & $4(1 \%)$ & $7(27 \%)^{*}$ & $5(2 \%)$ & $6(20 \%)^{\star}$ \\
ICU stay & $2(1-5)$ & $15(10-30)^{*}$ & $2(1-5)$ & $13.5(8.7-30)^{*}$ \\
Extubation failure & - & - & $18(6 \%)$ & $8(26 \%)^{*}$ \\
\hline
\end{tabular}

Data are reported as number with percent in parentheses for all variables except ICU stay, which are reported as median days and interquartile range. PPC = postoperative pulmonary complication; ICU = intensive care unit; $\mathrm{MV}=$ mechanical ventilation. ${ }^{*} \mathrm{P}<0.001$, success or $\mathrm{MV} \leq 48 \mathrm{~h}$ compared to failure or MV $>48 \mathrm{~h}$ (chi-square test).

Table 4. Multivariate analysis of risk factors for death, postoperative pulmonary complications and tracheostomy in the postoperative period of elective intracranial surgery.

\begin{tabular}{|c|c|c|c|c|c|c|}
\hline \multirow[t]{2}{*}{ Variable } & \multicolumn{2}{|r|}{ Death } & \multicolumn{2}{|r|}{ PPC } & \multicolumn{2}{|c|}{ Tracheostomy } \\
\hline & OR & $95 \% \mathrm{Cl}$ & OR & $95 \% \mathrm{Cl}$ & OR & $95 \% \mathrm{Cl}$ \\
\hline Extubation failure & 8.05 & {$[1.88 ; 34.36]^{*}$} & 11.18 & {$[2.27 ; 55.02]^{*}$} & 7.8 & {$[1.12 ; 55.07]^{*}$} \\
\hline $\mathrm{MV}>48 \mathrm{~h}$ & 0.21 & {$[0.03 ; 1.39]$} & 4.87 & {$[1.3 ; 18.18]^{*}$} & 0.62 & {$[0.78 ; 5.05]$} \\
\hline $\begin{array}{l}\mathrm{LC} \text { altered at } \\
\text { preoperative }\end{array}$ & - & - & 1.57 & {$[0.47 ; 5.25]$} & 7.0 & {$[0.80 ; 61.28]$} \\
\hline $\begin{array}{c}\text { LC altered at } \\
\text { extubation }\end{array}$ & 2.24 & {$[1.71 ; 25.78]^{*}$} & 7.06 & {$[2.26 ; 22.03]^{*}$} & 1.8 & {$[0.21 ; 15.4]$} \\
\hline Reoperation & 6.64 & {$[0.46 ; 10.87]$} & 0.75 & {$[0.14 ; 4.05]$} & - & - \\
\hline Age & 1.03 & {$[0.98 ; 1.07]$} & - & - & - & - \\
\hline Duration of surgery & - & - & 1.003 & {$[0.99 ; 1.00]$} & 1.01 & {$[0.99 ; 1.01]$} \\
\hline ICU stay & 1.04 & {$[0.99 ; 1.09]$} & 1.2 & {$[1.13 ; 1.35]^{*}$} & 1.16 & {$[1.07 ; 1.26]^{*}$} \\
\hline
\end{tabular}

$\mathrm{PPC}=$ postoperative pulmonary complication; $95 \% \mathrm{Cl}=$ confidence interval at $95 \%$; OR = odds ratio; $\mathrm{MV}=$ mechanical ventilation; $\mathrm{LC}=$ level of consciousness; ICU = intensive care unit. ${ }^{*} \mathrm{P}<$ 0.05 (multivariate analysis).

Prolonged MV is considered to be a risk factor for the development of pneumonia (21,27-29). A number of cardiac surgery studies have reported a higher incidence of respiratory complications in patients subjected to prolonged MV. Svensson et al. (30) found a $60 \%$ overall incidence of respiratory complications in the postoperative period following corrective surgery for thoracoabdominal aneurysm (atelectasis in $37 \%$, pleural effusion in $21 \%$, pneumonia in $9 \%$, pneumothorax in $8 \%$, and acute respiratory distress syndrome in $3 \%$ ). Money et al. (11) found a $68 \%$ incidence of pneumonia in patients subjected to prolonged $\mathrm{MV}$ in the postoperative period following surgery for a thoracoabdominal aortic aneurysm. Furthermore, Ingersoll and Grippi (1) reported a higher incidence of pulmonary atelectasis in cardiac surgery patients who underwent late extubation with more than $24 \mathrm{~h}$ of MV.

The development of postoperative pulmonary complications increases the cost of treatment for the patient or the public health-care system and considerably affects the prognosis. In an analysis of cost-effectiveness, Beauregard and Friedman (31) found that the development of postoperative pulmonary complications in elective craniotomy patients led to an overall increase in the cost of hospital care of at least US $\$ 4,026$ per patient.

In the present study, $70 \%$ of the patients who developed prolonged $\mathrm{MV}$ were found to require an additional surgical procedure. The most frequent cause of reoperation was cerebral edema with a need for decompressive craniotomy. 
It is likely that edema was due to increased intracranial pressure, which indicates a secondary complication of the surgery and requires an additional surgical approach.

There was a higher incidence of tracheostomy in patients who experienced extubation failure and required a prolonged period of MV. Tracheostomy is usually indicated when a prolonged period of $\mathrm{MV}$ is needed for $24 \%$ of the patients in ICUs $(32,33)$. According to our findings, the association of prolonged $\mathrm{MV}$ and extubation failure indicates a $98.8 \%$ likelihood of development of postoperative pulmonary complications, a $99.6 \%$ likelihood of a prolonged stay in the ICU during the postoperative period, a $74 \%$ chance of requiring further surgical interventions, a $56 \%$ chance of undergoing tracheostomy, and a $41 \%$ chance of dying. These results emphasize the need for a careful evaluation of patients with potential risk factors for extubation failure and prolonged MV during the postoperative period following elective intracranial surgery so that prophylactic strategies may be adopted. These conditions represent significant health-care costs.

One limitation of our study was the failure to determine the effect of development of postoperative pulmonary complications, which hinders us from inferring whether the duration of MV influenced the development of pulmonary complications or, on the contrary, whether the time spent on MV was prolonged by the presence of pulmonary complications. However, pneumonia attributed to $\mathrm{MV}$ in patients with encephalic lesions is known as "ventilator-associated pneumonia" and develops after 4 days on ventilatory support $(34,35)$. Because $67 \%$ of the 30 patients in our study who required prolonged MV needed 4 or more days of MV, we believe it was the prolonged MV that increased the incidence of pulmonary complications.

It is difficult to assume that extubation failure and prolonged MV were the only causes of all complications. Level of consciousness played an important role in the incidence
Table 5. Probability of the development of postoperative pulmonary complications, death, reoperation, tracheostomy, and prolonged ICU stay (greater than 5 days) in patients submitted to elective intracranial surgery according to the incidence of extubation failure and/or prolonged mechanical ventilation.

\begin{tabular}{lccc}
\hline & $\begin{array}{c}\text { Extubation } \\
\text { failure }\end{array}$ & $\begin{array}{c}\text { Prolonged mechanical } \\
\text { ventilation }\end{array}$ & $\begin{array}{c}\text { Probability } \\
(\%)\end{array}$ \\
\hline Postoperative pulmonary & Present & Present & 98.9 \\
complication & Present & Absent & 78.3 \\
& Absent & Present & 73.1 \\
& Absent & Absent & 10 \\
Death & Present & Present & 41.2 \\
& Present & Absent & 37.2 \\
& Absent & Present & 3.2 \\
Reoperation & Absent & Absent & 2.7 \\
& Present & Present & 74 \\
& Present & Absent & 28.2 \\
Tracheostomy & Absent & Present & 14 \\
& Absent & Absent & 2.2 \\
& Present & Present & 56.1 \\
& Present & Absent & 13.9 \\
& Absent & Present & 6.8 \\
Prolonged ICU stay & Absent & Absent & 0.9 \\
& Present & Present & 99.6 \\
& Present & Absent & 89.1 \\
& Absent & Present & 86.5 \\
& Absent & Absent & 15.6 \\
\hline
\end{tabular}

$\mathrm{ICU}=$ intensive care unit.

of death and postoperative pulmonary complications, indicating the impact of this variable on the outcomes.

Elective intracranial surgery patients who either experienced extubation failure or required prolonged MV had a higher incidence of postoperative pulmonary complications, reoperation and tracheostomy and required a longer period of time in the ICU. Level of consciousness and extubation failure were associated with death and postoperative pulmonary complications. Patients who required prolonged MV had a higher incidence of extubation failure.

\section{References}

1. Ingersoll GL, Grippi MA. Preoperative pulmonary status and postoperative extubation outcome of patients undergoing elective cardiac surgery. Heart Lung 1991; 20: 137-143.

2. Namen AM, Ely EW, Tatter SB, Case LD, Lucia MA, Smith $A$, et al. Predictors of successful extubation in neurosurgical patients. Am J Respir Crit Care Med 2001; 163: 658-664.

3. Vallverdu I, Calaf N, Subirana M, Net A, Benito S, Mancebo J. Clinical characteristics, respiratory functional parameters, and outcome of a two-hour T-piece trial in patients weaning from mechanical ventilation. Am J Respir Crit Care Med 1998; 158: 1855-1862.
4. Epstein SK. Decision to extubate. Intensive Care Med 2002; 28: 535-546.

5. Torres A, Gatell JM, Aznar E, El-Ebiary M, Puig de la Bellacasa J, Gonzalez J, et al. Re-intubation increases the risk of nosocomial pneumonia in patients needing mechanical ventilation. Am J Respir Crit Care Med 1995; 152: 137141.

6. Arozullah AM, Daley J, Henderson WG, Khuri SF. Multifactorial risk index for predicting postoperative respiratory failure in men after major noncardiac surgery. The National Veterans Administration Surgical Quality Improvement Program. 
Ann Surg 2000; 232: 242-253

7. Coplin WM, Pierson DJ, Cooley KD, Newell DW, Rubenfeld GD. Implications of extubation delay in brain-injured patients meeting standard weaning criteria. Am J Respir Crit Care Med 2000; 161: 1530-1536.

8. Yende S, Wunderink R. Causes of prolonged mechanical ventilation after coronary artery bypass surgery. Chest 2002; 122: 245-252.

9. Vidotto MC, Sogame LC, Calciolari CC, Nascimento OA, Jardim JR. The prediction of extubation success of postoperative neurosurgical patients using frequency-tidal volume ratios. Neurocrit Care 2008; 9: 83-89.

10. Crawford ES, Crawford JL, Safi HJ, Coselli JS, Hess KR, Brooks B, et al. Thoracoabdominal aortic aneurysms: preoperative and intraoperative factors determining immediate and long-term results of operations in 605 patients. $J$ Vasc Surg 1986; 3: 389-404.

11. Money SR, Rice K, Crockett D, Becker M, Abdoh A, Wisselink W, et al. Risk of respiratory failure after repair of thoracoabdominal aortic aneurysms. Am J Surg 1994; 168: 152-155.

12. Tobin MJ. Mechanical ventilation. N Engl J Med 1994; 330: 1056-1061.

13. Goodnough Hanneman SK. Multidimensional predictors of success or failure with early weaning from mechanical ventilation after cardiac surgery. Nurs Res 1994; 43: 4-10.

14. Hsieh AH, Bishop MJ, Kubilis PS, Newell DW, Pierson DJ. Pneumonia following closed head injury. Am Rev Respir Dis 1992; 146: 290-294.

15. Sogame LC, Vidotto MC, Jardim JR, Faresin SM. Incidence and risk factors for postoperative pulmonary complications in elective intracranial surgery. J Neurosurg 2008; 109: 222227.

16. Goldwasser R, Farias A, Freitas EE, Saddy F, Amado V, Okamoto V. [Mechanical ventilation of weaning interruption]. J Bras Pneumol 2007; 33 (Suppl 2S): S128-S136.

17. Pereira ED, Fernandes AL, da Silva Ancao M, de Arauja Pereres C, Atallah AN, Faresin SM. Prospective assessment of the risk of postoperative pulmonary complications in patients submitted to upper abdominal surgery. São Paulo Med J 1999; 117: 151-160

18. Rady MY, Ryan T. Perioperative predictors of extubation failure and the effect on clinical outcome after cardiac surgery. Crit Care Med 1999; 27: 340-347.

19. Akca O, Koltka K, Uzel S, Cakar N, Pembeci K, Sayan MA, et al. Risk factors for early-onset, ventilator-associated pneumonia in critical care patients: selected multiresistant versus nonresistant bacteria. Anesthesiology 2000; 93: 638-645.

20. Wijdicks EF, Borel CO. Respiratory management in acute neurologic illness. Neurology 1998; 50: 11-20.
21. McRitchie DI, Matthews JG, Fink MP. Pneumonia in patients with multiple trauma. Clin Chest Med 1995; 16: 135-146.

22. Croce MA. Postoperative pneumonia. Am Surg 2000; 66: 133-137.

23. Ewig S, Torres A, El-Ebiary M, Fabregas N, Hernandez C, Gonzalez J, et al. Bacterial colonization patterns in mechanically ventilated patients with traumatic and medical head injury. Incidence, risk factors, and association with ventilatorassociated pneumonia. Am J Respir Crit Care Med 1999; 159: 188-198.

24. Woratyla SP, Morgan AS, Mackay L, Bernstein B, Barba C. Factors associated with early onset pneumonia in the severely brain-injured patient. Conn Med 1995; 59: 643-647.

25. Franceschini J, Sogame LCM, Gazzotti MR, Vidotto MC, Jardim JR. Pulmonary function and thoraco-abdominal configuration after elective craniotomy. Neurosurg Q 2008; 18: 22-27.

26. Gazzotti MR, Vidotto MC, Sogame LC, Hayashi LY, Jardim JR. [Vital capacity reduction in postoperative of elective craniotomy]. Rev Neurol 2008; 47: 124-128.

27. Sogame LC, Faresin SM, Vidotto MC, Jardim JR. Postoperative study of vital capacity and ventilation measurements following elective craniotomy. São Paulo Med J 2008; 126 : 11-16.

28. Celis R, Torres A, Gatell JM, Almela M, Rodriguez-Roisin $\mathrm{R}$, Agusti-Vidal A. Nosocomial pneumonia. A multivariate analysis of risk and prognosis. Chest 1988; 93: 318-324.

29. Franco CAB, Pereira J, Torres B. Pneumonias adquiridas em ambiente hospitalar. J Pneumol 1998; 24: 73-86.

30. Svensson LG, Hess KR, Coselli JS, Safi HJ, Crawford ES. A prospective study of respiratory failure after high-risk surgery on the thoracoabdominal aorta. J Vasc Surg 1991; 14: 271282.

31. Beauregard CL, Friedman WA. Routine use of postoperative ICU care for elective craniotomy: a cost-benefit analysis. Surg Neurol 2003; 60: 483-489.

32. Heffner JE, Miller KS, Sahn SA. Tracheostomy in the intensive care unit. Part 1: Indications, technique, management. Chest 1986; 90: 269-274.

33. Heffner JE. Medical indications for tracheotomy. Chest 1989; 96: 186-190.

34. Drakulovic MB, Torres A, Bauer TT, Nicolas JM, Nogue S, Ferrer M. Supine body position as a risk factor for nosocomial pneumonia in mechanically ventilated patients: a randomised trial. Lancet 1999; 354: 1851-1858.

35. Eberhardt KE, Thimm BM, Spring A, Maskos WR. Dosedependent rate of nosocomial pulmonary infection in mechanically ventilated patients with brain oedema receiving barbiturates: a prospective case study. Infection 1992; 20: 12-18. 